\title{
DESIGN OF ECR ION SOURCE VACUUM SYSTEMS
}

\author{
Juraj Pivarč * \\ Joint Institute for Nuclear Research, FLNR, Dubna \\ Head Post Office, P.O.Box 79, 101000 Moscow, Russia
}

\begin{abstract}
The present work has been motivated primarily by the discussions and results reported by M.CAVENAGO [1] and K.HATANAKA et al., [2] who indicate the requirements for vacuum systems of ECR ion sources. To use such source as a possible source of high charge state ions is very interesting on upgrading present heavy particle accelerators. The relevance of ion induced pressure instability and neutral gases processes is given.
\end{abstract}

\section{INTRODUCTION}

The vacuum system of the ECR ion source is one of the main component of the source. Whereas, operating pressure ranges for vacuum systems of accelerators are $10^{-4}-10^{-9} \mathrm{~Pa}[3]$, the required operating pressure range for the vacuum system of the ECR ion source is $10^{-2}$. $10^{-5} \mathrm{~Pa}$, respectively. Basically, it consists of stainless steel, cooper beam tubes pumped with turbomolecular, cryosorption, getter - Ti - sublimation, NEG pumps combined with sorption and rotary pumps. The combination of turbomolecular and rotary pumps is being used for the time in the DECRIS ion source [4]. The other suitable combinations of vacuum pumps as well as the pressure measuring gauges are shown in Figure 1.

The paper is mainly oriented to more detail description of influence of gas desorption process (ion induced pressure instability) and neutral gases on the vacuum system design of the ECR ion sources.

\section{DESORPTION OF GASES}

The pressure of $10^{-5} \mathrm{~Pa}$ must be maintained inside the ECR ion source and its beam pipe despite of i) the thermal outgassing of surfaces, ii) outgassing due to the desorption of weakly bounded molecules on the walls of the vacuum system, iii) the ions induced by extracted and accelerated ions, iv) the diffusion of hydrogen from the walls of the vacuum system, iiv) the neutral gases produced inside the plasma of the ECR ion source, as well as ivv) the desorption of molecules generated by a roentgen radiation. There are also observed direct thermal effects produced by the radiation. The radiation is also penetrating to the region of the beam pipe of the

\footnotetext{
* Home address : Institute of Physics, Slovak Academy of Sciences, Dúbravská cesta 9,842 28 Bratislava, Slovakia.
}

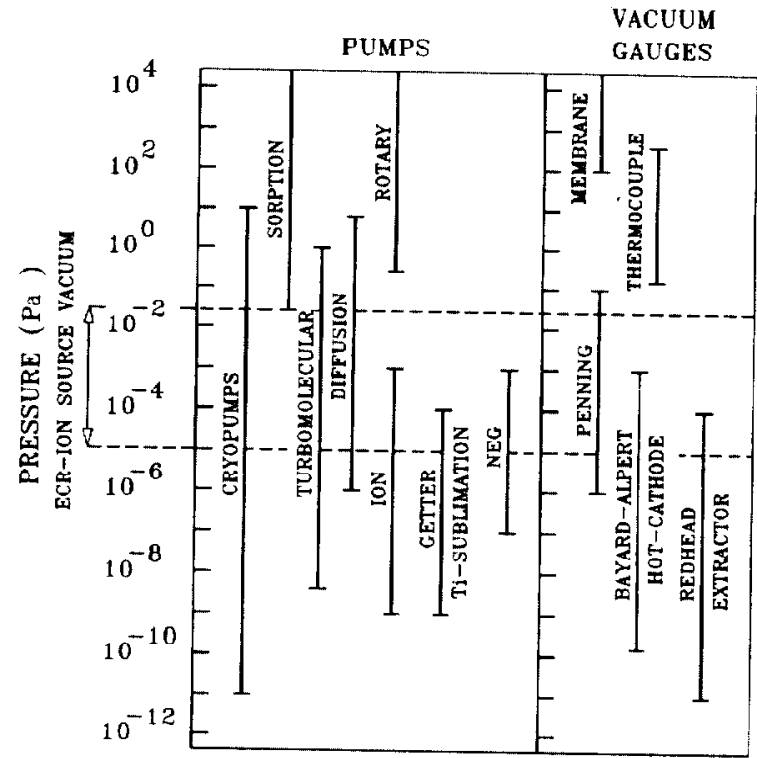

Figure 1. Vacuum pumps and gauges used for pumping and pressure measurement in ECR ion sources.

ECR ion source through the orifices in the anode and the extraction system of the source. Therefore, even watercooling parts of the first and second stages and other small areas of the source, as for example the input flange of the high frequency generator, can be above ambient temperature by $80^{\circ} \mathrm{C}$ or more with a corresponding increase in their thermal outgassing rate by an order of magnitude or more [5-6]. To establish the given pressure for the given pumping speed the average thermal outgassing rate and the total average desorption rate must be below certain definite values.

\section{A. Ion - induced pressure instability}

The ions induced by extracted and accelerated beam can produce desorption of strongly bound molecules. The desorption flow rate $n_{1}, Q_{1}$ can be expressed by [7]

$\mathrm{n}_{1}=\eta \sigma L(\mathrm{I} / \mathrm{e}) \mathrm{n}$ or $\mathrm{Q}_{1}=\eta \sigma \mathrm{L}(\mathrm{I} / \mathrm{e}) \mathrm{p}$

where $\eta$ is the molecular desorption yield [molecules ion $^{-1}$ ], $\sigma$ is the ionisation cross-section of extracted and accelerated ions $\left[\mathrm{m}^{2}\right]$ ( for example for high energy protons $\sigma=1.2 \times 10^{-22} \mathrm{~m}^{2}$ and for $\mathrm{CO}$ [3] ) $\mathrm{L}$ is the length of beam section $[\mathrm{m}], \mathrm{I}$ is the beam intensity [A], $e$ is the 
electron charge [As], $\mathrm{n}$ is the number of molecules in unit volume $\left[\mathrm{m}^{-3}\right]$ and $\mathrm{p}$ is the pressure [Pa]. Note, if ions are taken from the restgas, hence $\eta$ will represent a net desorption yield. For $\eta<0$ "beam pumping" can be observed, i.e. the system acts like an ion pump. In the presence of the ion induce - desorption is $\eta>0$ and the equilibrium pressure can be expressed as

$\mathrm{p}=\mathrm{Q} / \mathrm{S}_{\mathrm{eft}}=\frac{\eta \sigma(\mathrm{I} / \mathrm{e}) \mathrm{p}+\mathrm{qA}}{\mathrm{S}_{\mathrm{eff}}}$

which gives

$$
\mathrm{p}(\mathrm{I})=\frac{\mathrm{p}_{0}}{1-\frac{\sigma}{\mathrm{e}} \frac{\eta I}{S_{\text {eff }}}}
$$

where $p_{0}=q A / S_{\text {eff }}$.

By introducing

$$
(\eta \mathrm{I})_{\mathrm{rnt}}=\frac{e}{\sigma} S_{e r f}
$$

we obtain

$$
p=\frac{P_{0}}{1-\frac{\eta I}{(\eta I)_{\text {crit }}}} .
$$

Hence, the "critical current" product for $S \rightarrow \infty$ cannot exceed

$$
(\eta \mathrm{I})_{\mathrm{erit}}=\frac{\mathrm{e}}{\sigma \mathrm{w}} \mathrm{L}^{2} \text {. }
$$

Therefore, the pressure $p$ is a function of the beam current I. The higher is the current $I$, the higher is the equilibrium pressure $p$. The conductance of the beam pipe and the pump distance are also crucial parameters for vacuum stability. The remedy "defect" caused by the pressure bumps in the vacuum system of the source can be reduced by adding cryogenic, getter $-\mathrm{Ti}$-sublimation , or NEG pumps, respectively [8-9]. By $300{ }^{\circ} \mathrm{C}$ bakeout and argon glow discharge cleaning of the source stages and beam pipes we can also reduce the molecular desorption yield $\eta$. By the way the required ion dose on the beam pipe is typically $10^{18} \mathrm{~cm}^{-2}$ and result in that $\eta<0$.

The glow discharge cleaning could be done as shown in Figurc 2. The discharge gas argon gives efficient sputtering and desorption of strongly adsorbed gas molecules. On the other hand the addition of oxygen produces from carbon contaminants on the surface $\mathrm{CO}$ and $\mathrm{CO}_{2}$ which can easily be pumped out.

The other very important sources of gases in the ECR ion sources are neutral gases.

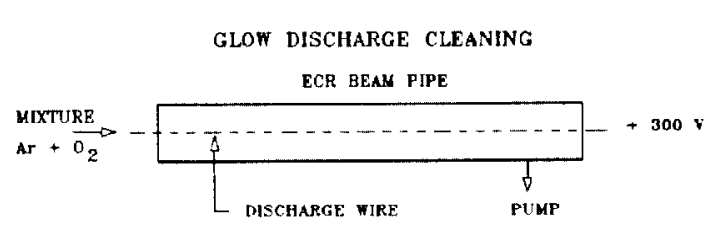

Figure 2. Layout of the glow discharge cleaning [3].

\section{NEUTRAL GASES}

The neutral gases can arisc for example by recombinations of ions with electrons. The efficiency of the process is very high at the low energy of electrons and sufficiently long time of interactions of produced ions with electrons. At the low electron temperature the neutral gases strongly influence on the balance of the plasma which is created from charge particles.

The ion - loss rate due to the recombination process can be described by the following equation [10]

$$
\frac{\partial n^{+}}{a t}=-\alpha n^{+2}
$$

where $\mathrm{n}^{+}$is the concentration of the ions $\left[\mathrm{cm}^{-3}\right], t$ is the time [s] and $\alpha$ is the coefficient of recombination $\left[\mathrm{cm}^{3} \mathrm{~s}^{-1}\right]$. The coefficient $\alpha$ may be approximated by

$\alpha \equiv \frac{10^{-13}}{\sqrt{T_{e}}}$

where $T_{e}$ is the temperature of electrons into the plasma $[\mathrm{eV}]$. For the typical values reached in the ECR ion source is $\mathrm{n}^{+} \cong 5 \times 10^{10} \mathrm{~cm}^{-3}[11], \mathrm{T}_{\mathrm{e}} \cong 5000 \mathrm{eV}[12], \alpha \cong$ $1.4 \times 10^{-15} \mathrm{~cm}^{3} \mathrm{~s}^{-1}$, and at the volume of the second stage of the ECR ion source of $1500 \mathrm{~cm}^{3}$ (DECRIS), the

desorption rate $\frac{d Q^{\text {ng }}}{d t}$ will be given by

$\frac{\mathrm{dQ}_{1}^{\mathrm{ag}}}{\mathrm{dt}}=2 \times 10^{-8} \mathrm{Pals}^{-3}$

The neutral gas is also generated as a residual gas from the usage gas flow rate. The usage rate for the solid and gas materials is varied depending on a variety of parameters. It has generally been confirmed by most of tests that the usage rates for many solid materials are approximately $1 \mathrm{mg} \mathrm{h}^{-1}$ [13]. It corresponds to consumption of

$$
\frac{\mathrm{dQ}_{2}^{\mathrm{ng}}}{\mathrm{dt}}=2.5 \times 10^{-3} \mathrm{Pal} \mathrm{s}^{-1}
$$

The lowest usage rate has been obtained $0.1 \mathrm{mg} \mathrm{h}^{-1}$ for a calcium run. The usage rate for gaseous materials are 
approximately $0.06 \mathrm{~cm}^{3}$ (STP) $\mathrm{min}^{-1}$ [14]. It corresponds to a maximum consumption of

$$
\frac{\mathrm{dQ}_{3}^{\mathrm{ng}}}{\mathrm{dt}}=0.1 \mathrm{Pals}^{-1}
$$

So, the total neutral gas $\frac{\mathrm{dQ}_{\mathrm{t}}^{\mathrm{ng}}}{\mathrm{dt}}$ for the gaseous materials operation is given by

$$
\frac{\mathrm{dQ}_{\mathrm{t}}^{\mathrm{ng}}}{\mathrm{dt}}=\frac{\mathrm{dQ}_{1}^{\mathrm{ng}}}{\mathrm{dt}}+\frac{\mathrm{dQ}_{3}^{\mathrm{ng}}}{\mathrm{dt}} \cong 0.1 \mathrm{PaI} \mathrm{s}^{-1}
$$

In order to obtain suitable operation vacuum inside the beam pipe of the ion source of $10^{-4} \mathrm{~Pa}$ the effective pumping speeds for the solid material $\left(S_{\text {eff }}^{s}\right)$ and the gaseous $\left(\mathrm{S}_{\mathrm{eff}}^{\mathrm{g}}\right)$ operations have to be related by $\mathrm{S}_{\mathrm{eff}}^{\mathrm{s}} \cong 25$ $1 \mathrm{~s}^{-1}$ and $S_{\text {eft }}^{\mathrm{g}} \cong 10001 \mathrm{~s}^{-1}$, respectively.

\section{OUTGASSING OF THE BEAM PIPE}

For every vacuum system the size of the required pumps is directly related to the outgassing. The first imported source is the static and thermal outgassing of weakly adsorbed molecules and diffusion of $\mathrm{H}_{2}$ from the bulk of the material. The standard procedure to reduce the thermal outgassing is the well known bakeout of the beam pipe. The pressure inside an unbaked system is mainly determined by water vapour. In a clean and well baked system $\mathrm{H}_{2}$ will be the dominant residual gas constituent. Typically total specific outgassing rate $\mathrm{q}$ for unbaked $100 \mathrm{~h}$ pump down beam pipe constructed by stainless steel is $10^{-7} \mathrm{Pal} \mathrm{s} \mathrm{s}^{-1} \mathrm{~cm}^{-2}$ at $293 \mathrm{~K}$ (q for baked 30 - $150 \mathrm{~h}$ pump down beam pipe constructed by the same material at $573 \mathrm{~K}$ is $10^{-10} \mathrm{~Pa} 1 \mathrm{~s}^{-1} \mathrm{~cm}^{-2}$ ) [3].

The second important source of gas in ion source is the so called "dynamic" outgassing in presence of the beam. Here, strongly bound molecules can also be desorbed.

The quantity of the outgassing rate very strongly also depends on the finished treatment with used materials. However, in order to obtain the outgassing rate less as $10^{-8} \mathrm{~Pa} \mathrm{~s}^{-1} \mathrm{~cm}^{-2}$ the vacuum system is not allowed to be constructed by rubbers, polyamids, epoxy, viton and PFTE materials, respectively.

\section{CONCLUSION}

In practice, it is very difficult to construct very effective, reliable and cheap vacuum system for the ECR ion source. The vacuum system of the source have to be designed with respect of obtaining the vacuum of $10^{-5} \mathrm{~Pa}$, for about $10 \mathrm{~h}$ with a leak rate lower than $10^{-3} \mathrm{Pals} \mathrm{s}^{-1}$ and the outgassing rate of the vacuum exposed surfaces lower than $10^{-7} \mathrm{~Pa}^{-1} \mathrm{~cm}^{-2}$ The plasma tubes and beam tubes must be made of stainless steel, steel with stable structure and with a low relative magnetic permeability. The aluminium and cooper can also be successfully used because of good mechanical properties, availability and very low desorption rates.

As, it is practically impossible to separate the effects of diffusion, outgassing, and permeation which are manifold higher in polymers as in metals [15], it is not recommended to use polymers for clean interior surfaces of the ECR ion source vacuum system.

\section{REFERENCES}

[1] M. Cavenago, "Operation of the Legnaro ECR ion source, " Proc. of the 3rd European Part. Acc. Conf. (EPAC 92), Vol. 2, Berlin , 24 - 28 March, 1992, pp. 984 - 986. Editors: H. Henke, H. Homeyer and Ch. Petit-Jean-Genaz. Printed in Singapore by Fong and Sons Printers Pte. Ltd. 1992.

[2] K. Hatanaka and H. Nonaka, "Status of the RIKEN ECRIS, "Proc. of the Int. Conf. on the Physics of Mult. Charged Ions and Int. Workshop on ECR IS, Grenoble, Sept. 12 - 16, 1988, pp. 827 - 838.

[3] O. Gröbner, "Vacuum systems, "Report CERN 85 19,Geneva 1985 , pp. 489.

[4] A.A. Efremov, A.I. Ivanenko, V.B. Kutner, J. Pivarč and K.D. Tumanov, "Vacuum system for the Dubna ECR ion source DECRIS-14." Proc. of the 3rd European Part. Acc. Conf. (EPAC 92), Vol. 2, Berlin, 24 28 March, 1992 , pp. 1567 - 1569. Editors: H. Henke. H. Homeyer and Ch. Petit-Jean-Genaz. Printed in Singapore by Fong and Sons Printers Pte. Ltd., 1992.

[5] G. Egelmann, M. Genet and W. Wahl, J. Vac. Sci, and Technol. A, 5.2337 (1987).

[6] B.A. Trickett, Vacuum 28, 471 (1978).

[7] I. Pivarč, Jemná mechanika a optika 4, 121 (1988) (in Slovak).

[8] F. Donni. C. Boffito and B. Ferrario, J. Vac. Sci. and Technol. A, 4, 2447 (1986).

[9] M. E. Malinowski, J. Vac, Sci. and Technol. A, 3, 483 (1985).

[10] J.P. Rajzer, Fizika gazorogo razrjada (Moscow, Science, Main Redaction of the Physics-Mathematics Literature, 1987, pp. 130) (in Russian).

[11] R. Becker, E.D. Donets and G.D. Schirkov, "The ion cooling in EBIS", Report E-9-91-382, JINR Dubna, Russia.

[12] R. Geller, B. Jacquot and M. Pontonnier, Rev. Sci. Instr. 56, 1505 (1985).

[13] R.C. Pardo and P.J. Billquist. Rev. Sci. Instr. 61, 239 (1990).

[14] V.B. Kutner, private communication (1991) (in Russian).

[15] R.N. Peacock, J. Vac. Sci. and Technol. A, 17, 330 (1980). 